\title{
REINFORCEMENT OF LAMINATED GLASS FACADES AGAINST THE BLAST LOAD
}

\author{
Jalal NAKHAEI ${ }^{\mathrm{a}}$, Saeed FORGHANI ${ }^{\mathrm{b}}$, Mahdi BITARAFAN ${ }^{\mathrm{c}}$, \\ Shahin LALE AREFI ${ }^{\mathrm{d}}$, Jonas ŠAPARAUSKAS ${ }^{\mathrm{e}}$ \\ ${ }^{a}$ Department of Art and Architecture Engineering, Islamic Azad University, Central Tehran Branch, Iran \\ ${ }^{b}$ Department of Civil Engineering, Malek-Ashtar University of Technology, Tehran, Iran \\ ${ }^{c}$ Department of Civil Engineering, Research Institute of Shakhes Pajouh, P.O. Box 81655-1537, Isfahan, Iran \\ ${ }^{d}$ Department of Civil Engineering, University of Mohaghegh Ardabili, P.O. Box 56199-11397, Ardabil, Iran \\ eDepartment of Construction Technology and Management, Vilnius Gediminas Technical University, \\ Sauletekio al. 11, LT-10223 Vilnius, Lithuania
}

Received 19 Jun 2015; accepted 30 Sep 2015

\begin{abstract}
The first defensive element of the building against the explosion is the façade. On the condition that façade is not resistant against explosion and encounters the damage, the blast wave will enter the construction and increases financial losses and casualties. With respect to that glass facades do not possess adequate strength under the explosion; the major aim of the study is to examine variety of the reinforcement practices of glazing facades with the laminated glass subjected to the blast wave. The investigation has been done by two descriptive and simulation approaches with the finite element software of AutoDyn and eight simulations has been represented in the subject of laminated glasses. In addition, through AHP method, related questionnaires were designed so that some experts including 31 people possessing the activity and investigation background of two to thirty years in the civil protection scope answered them. Considered indexes in AHP model consist of resistance against explosion, passed light rate, expenditure, complexity and difficulty of accomplishment so that in the resistance part versus explosion, the results of numerical simulation have been benefited. Outcomes demonstrate the best function in laminated glass models belongs to the overlapped louvered opening model. Afterwards, the model of two-layer laminated glass with the spring is laid. Furthermore, the most economical model which supplies the most light as well as the most safety is the model of one-layer laminated glass with spring.
\end{abstract}

Keywords: laminated glass, facade, blast load, numerical modelling, building, AHP method.

\section{Introduction}

Due to expansion of threats in all over the world, the necessity of safe structures with less vulnerability is led to the growth. Glazing facades are applied because of architectural and beautiful features which they provide, whereas the glass is a completely brittle and fragile material. Although it has quite high pressure resistance, its tensile strength is limited and for this reason, it has very low resistance under blast waves (Bedon et al. 2014). On the other hand, when these kinds of glasses are broken and disrupted, they're converted into too sharp and dangerous fragments with high speed. The history has revealed most injuries caused by explosion are due to these fragments (Smith 2001). Thus, according to occurred incidents, it can be mentioned that glasses of building windows are the weakest parts of the structure compared to other structural parts and consequently, it will be the most vulnerable ones under blast waves (Zhang et al. 2013). It must be noted that the first defensive element of the building against the explosion is the façade that if it has sufficient resistance versus explosion, the forces will be transferred to the columns and the roof via external walls and then to the foundation via the structure. On the condition that façade is not resistant against explosion and gets involved the damage, the pressure and the wave of explosion will enter the structure, directly so that leads to serious losses for occupants and the structure. Therefore, it's indicated the appropriate designing of the structure façade under explosion will have a considerable effect on the decline of financial losses and casualties.

With regard to that glazing facades do not have sufficient resistance under the explosion; the main problem in the paper is that how to create a façade with glass materials in order to contain enough strength against blast loads in that can either damp the blast force approximately and transmits it to the structure, or completely resists against explosion, and entirely transmits the load to the structure. On the other hand, it's proven that laminated

Corresponding author: Jonas Šaparauskas

E-mail: jonas.saparauskas@vgtu.lt 
glasses are very effective in reduction of these hazards (Hooper et al. 2012) and presently, to protect occupants of the building, they are used. These glass types have considerable resistance versus blast loads even after glass layers are broken. In this direction, it's concentrated on the variety of executive approaches of reinforcement in facades with the laminated glass under explosion. ASTM F 2248-09 (2010), UFC 4-010-01 (2008), UFC 3-34002 (2013) and UK Glazing Hazard Guide (1997) are the newest standards applied in designing of glass façades subjected to the explosion. But, since these standards are based on analysis of simplified equivalent one degree freedom system, they consist of conservative designs.

ASTM F 2248-09 (2010) has provided an especial framework for designing glazing façades against explosion by laminated and insulated glasses. First the equivalent designing load must be chosen for a particular quantity of the explosive material and a specified distance. Afterwards, the relative graph must be selected from ASTM E 1300-09a (2010) to acquire laminated glass thickness. Hence, this standard is applicable just for laminated glasses with the internal layer of PVB and efficiency of laminated gasses has not been assessed with different materials. On the other hand, these designing graphs are limited to laminated glasses with maximum length and width of 4 and 5 meters. UFC 4-010-01 (2013) has stated the blast strength of laminated glasses for a special blast load through the dynamic analysis, tests and the approach represented in ASTM F 2248-09 (2010). According to UFC 4-010-01 (2008) standard besides laminated glasses, polycarbonate glasses are designed. UFC 3-340-02 (2013) pays to only designing of completely consolidated glazing façades under explosion. Designing graphs of this standard can determine thickness of the glass on the basis of stress and continuity length of blast pressure phase. By the way, maximum considered length and width are 3 and 1.5 meters in order. But, the standard of UK Glazing Hazard (1997) with respect to the glass behavior after cracking subjected to blast loads, has applied the more realistic practice for designing of laminated glass façades. However, this guide is limited to martial applications and in addition to some finite numbers of window measures.

In recent years, some studies have been done about dynamic properties of the glass under loads with high strain rate. Beason and Morgan (1984) offered a model for glass failure prediction. Moreover, since tensile strength of the glass is much affective on its behavior, Overend and Zammit (2012) expressed a computational algorithm for determining tensile resistance of the glass. In addition, Peroni et al. (2011) did a numerical investigation concerning high strain-rate behavior of the glass which aids modeling the behavior of the glass under blast loads. Also, Zhang et al. (2012) did laboratory test for determining dynamic material properties of the glass.

Kranzer et al. (2005) carried out experimental investigations and tests on resistant glazing systems against explosion in which only one kind of laminated glass with $7.5 \mathrm{~mm}$ thickness has been considered. Wei et al. (2006) analyzed disruption of glass façade under blast loading and evaluated disruption possibility of laminated and united glasses and under blast loads. Layers of the glass and its internal layer (PVB) behave in the elastic and viscous-elastic forms, in order. LS-DYNA3D software has been employed for analysis and based on the amassed damage theory of Weibull, failure possibility of the glass and its internal layer has been described. The influences of parameters such as the explosion, geometry and glass material on the failure possibility have been expressed and these outcomes can be applied to decrease blast risk on the glass. Wu et al. (2010) carried out a numerical study on dynamic disruption of laminated glasses enhanced by nanomaterials under impulsive loads that this research pays to application of nanomaterial for enhancement of these glass types.

Other studies in this field are done by Lusk et al. (2011), Larcher et al. (2012) who carried out numerical and experimental investigations on laminated glasses under blast loading. In the paper, several numerical models for disruption simulation of the glass and its internal layers have been utilized. In addition, experimental models of this glass subjected to blast loads have been applied to validate numerical outcomes. The results of the research demonstrate the simulated layered model can predict experimental outcomes well and there is a suitable conformity between experimental and numerical outcomes. These outcomes have been also evaluated in 3-D state. Hidallana-Gamage et al. (2013a, 2013b) did a study about computational analysis of laminated glass panels under blast loads in where two-dimensional and threedimensional modeling approaches on the laminated glass have been compared. Hidallana-Gamage et al. (2014a) in the continuation of the previous study, research about numerical modeling and analysis of blast performance of laminated glass panels and the influence of its material properties. This research explains a comprehensive practice to state the response and behavior of laminated glass panels versus explosion and indicates the influence of important material parameters of the glass. The behavior after cracking of panels and the aid of the internal layer towards blast resistance have been discussed. Achievements of the study demonstrate tensile strength of the glass considerably affects the blast resistance of panels and this is while material properties of the internal layer possess noticeable influence on the response under the blast load. First, the glass of the panel approximately absorbs the blast energy; but after the glass failure, the internal layer transforms more and absorbs more blast energy. The important point is that panels must be designed so that failure and disruption of the glass and its internal layer occur before disruption in bases means the frame zone in order to obtain the desirable safety level. Thus, material properties of the glass, internal layer and seal in interconnection the glass to the frame play an im- 
portant role in the blast resistance. Moreover, HidallanaGamage et al. (2014b) did another study concerning failure analysis on laminated glass panels under blast loads. This paper has expressed a reliable and accurate analysis approach for studying on the response of laminated glass panels and disruption prediction of their segments under the influence of the blast load. This procedure has been resulted of the finite element techniques. The main tension $\sigma 11$ as the glass failure criterion and phone misses tension $\sigma 7$ for the internal layer and seal are used. The outcomes resulted by the finite element analysis of the middle point leap of the glass, energy absorption in the crisis points of the glass, internal layer and seal have been represented. These outcomes have been compared with the practical outcomes of others' studies. The results indicate the tensile strength of the glass $\mathrm{T}$ has an important influence on panels' behavior and glasses have absorbed $80 \%$ of the energy.

Zhang et al. (2013) carried out a parametric study to determine the response of laminated glass windows against blast loads. In the study, numerical simulation has been done for drawing pressure-impact (P-I) graphs in laminated glass windows to provide relations between dynamic response of laminated glass windows and blast loading. Simulation is based on LS-DYNA software. Parametric studies have been done in order to assess the influence of measures of the window, thickness of the internal layer, thickness of the glass and condition of the base (frame) on the pressure-impact graph. The results demonstrate that these relations can be benefited in order to prepare pressure-impact graphs and evaluate blast resistance capacities of laminated glass windows.

In the whole mentioned papers, the quality, dimensions, layer numbers and other dynamic material properties of the glass and internal layer have been discussed; besides methods for modeling of these glass kinds; whereas a strategy for reinforcement as better as possible of these glasses versus high blast loads has not been stated. Hence, the study has concentrated on this issue.

\section{Methodology}

The applied approach in this research was chosen from the compound type. In other words, two study methods of descriptive and simulated research were utilized. Borg and Gall (1989) divided descriptive studies into three groups of Profile Method, Linear Method and Delphi Method. As mentioned, the other applied approach in the research is simulation method. Considering the high fabrication expenditure of laboratory models, the finite element models are the most appropriate method for assessment of the blast behavior of the structures. The application scope of this method is limited to investigative exertions. Of course, nowadays, majority of blast investigative software is based on the finite element analysis and because of high accuracy of these pieces of software like AutoDyn and their updating; this method has been used in the computer modeling form in this research.

\subsection{AHP analysis method}

AHP was spread by Saati (Saati, Wind 1980). The main point of this method is how relative importance of a set of activities in a multi-criteria decision-making problem is determined. According to this method, decision maker is able to combine judgments around intangibly qualitative criterion with tangibly quantitative criterion and translate (Badri 2001).

AHP method is based on three phases: first, structure of the model; second, comparative judgment on choices and criteria; third, combination of priorities (Dağdeviren 2008). In the first step, a complicated decision-making problem is formed as a hierarchical tree. This process divides a complex decision-making problem into the hierarchy of goals, criteria and choices. These factors of decision-making create a hierarchical structure including the goal in the highest point, criteria in the middle and alternatives in the lowest point. In the second step, alternatives and criteria are compared to each other. In AHP, comparisons are based on the standard nine-scale (see Table 1).

Table 1. Standard nine scale of importance degree and definition (Saati, Wind 1980)

\begin{tabular}{l|c}
\hline \multicolumn{1}{c|}{ Definition } & Importance degree \\
\hline Equal importance & 1 \\
\hline Fairly more importance & 3 \\
\hline More importance & 5 \\
\hline Much more importance & 7 \\
\hline Extremely more importance & 9 \\
\hline Medium quantities & $2,4,6,8$ \\
\hline
\end{tabular}

If $c=\left\{c_{j} \mid j=1,2, \ldots, n\right\}$ is a set of criteria, results of the paired comparison on $n$ criteria can be placed into an evaluation matrix $A$ with $(n \times n)$ columns and rows that each factor equals the quotient of criteria weights, As shown in Eqn (1):

$$
\begin{gathered}
A=\left[\begin{array}{ccc}
\alpha_{11} & \alpha_{12} & \cdots \alpha_{1 n} \\
\alpha_{21} & \alpha_{22} & \cdots \alpha_{2 n} \\
\alpha_{n 1} \vdots & \alpha_{n 2} & \cdots \alpha_{n n}
\end{array}\right], \\
\alpha_{i i}=1, \quad \alpha_{j i}=\frac{1}{\alpha i j}, \quad \alpha_{i j} \neq 0 ; \\
\alpha_{i j}\{i, j=1,2, \ldots, n\} .
\end{gathered}
$$

In the third step, the mathematical trend starts to normalize and find relative weights for each matrix. The relative weights are gained by the special vector $(w)$ according to the largest special quantity $\left(\lambda_{\max }\right)$ as the following:

$$
A w=\lambda_{\max } w, \lambda_{\max }=n .
$$

Providing paired comparisons are completely compatible, matrix $A$ gains rank 1 and in this condition, 
weights can be obtained through normalization of each of rows and columns of matrix $A$ (Wang, Yang 2007). The output quality of AHP emphatically depends on compatibility of judgments of paired comparisons (Dağdeviren 2008). Compatibility is defined with relations between data of matrix $A$ :

$$
\alpha_{i j} \times \alpha_{j k}=\alpha_{i k} .
$$

Constant index $(C I)$ equals:

$$
C I=\left(\lambda_{\max }-n\right) /(n-1)
$$

Final compatibility ratio $(C R)$ resulted by each one, according to whether done assessments are acceptable enough, is calculated as the ratio of $C I$ to $R I$ (Random Index), shown in Eqn (4):

$$
C R=C I / R I
$$

Quantity of $C R$ index must be less than 0.10 so that AHP results can be acceptable (Işılar, Büyüközkan 2007). Providing that final compatibility ratio is more than this quantity, assessment trend must be reiterated to improve the constant (Dağdeviren 2008). $C R$ index can be applied to compute the compatibility for decision makers. The recent developments in the decision-making models based on the AHP method are listed below:

- Bitarafan et al. (2012) used AHP technique in reconstructing damaged areas in natural crises;

- Wang et al. (2013) applied the AHP method to support the best best-value contractor selection;

- Gudienè et al. (2014) identified and evaluated the critical success factors for construction projects in Lithuania by using AHP approach;

- Nakhaei et al. (2015) selected the best urban tunnels as safe space in crisis by using AHP method;

- Polat (2015) performed subcontractor selection using the integration of the AHP and PROMETHEE methods.

In AHP approach, related questionnaires were provided so that some experts including 31 people possessing the activity and investigation background of two to thirty years in the civil protection, civil and architectural engineering scope answered them. The number of experts has been selected by Kukeran formula. It has been wanted to compere indexes with each other on questionnaires. Considered indexes in AHP model consist of resistance against explosion (X1), passed light rate (X2), expenditure (X3), complexity (X4) and difficulty of accomplishment (X5) so that in the resistance part versus explosion, the results of numerical simulation have been benefited. In addition, experts compared 8 alternatives in each of indexes that comparisons were performed via numbers 1 to 9 according to Table 1 .

\subsection{Simulation method}

To assess the models, it can't be satisfied with the results of the questionnaire, because their behaviors are very complicated against explosion and depend on many factors. Therefore, the models were simulated by the finite element software of AutoDyn that in the following, it is pointed to the simulation procedure of these models. With respect to these factors affecting on the glazing façade behavior under the blast wave, in this research, eight finite element models have been constituted to decline the influence of the blast wave. For accurate assessments of blast load influences on the glazing façade, nonlinear material have been employed.

\section{Glass material}

To simulate the glass, in the paper, the material of Float Glass available in the material library of AutoDyn was applied. Float Glass material possesses the initial density of $2530 \mathrm{~kg} / \mathrm{m}^{3}$ and uses the statement equation of Polynomial to describe its expansive behavior. This type of statement equation is the overall form of Mie-Gruneisen statement equation that certainly possesses several equations for states of pressure and tension.

The resistance model of this material is JohnsonHolmquist model applicable for modeling brittle and fragile materials such as glass and concrete under high pressures and high tension and strain rate. The profile module of 3.04e $4 \mathrm{MPa}$ and Hogunit Elastic limit of $5.95 \mathrm{e} 3 \mathrm{MPa}$ have been come in this criterion (see Table 2). In addition, to define the disruption behavior, the disruption criterion of Johnson-Holmquist has been applied (Holmquist et al. 1995).

Table 2. Float Glass characteristics

\begin{tabular}{l|l}
\hline \multicolumn{2}{c}{ Float Glass characteristics } \\
\hline Density & $2530 \mathrm{~kg} / \mathrm{m}^{3}$ \\
\hline Elasticity module & $5.95 \mathrm{e} 3 \mathrm{MPa}$ \\
\hline Shear module & $3.04 \mathrm{e} 4 \mathrm{MPa}$ \\
\hline Tensile strength & $150 \mathrm{a}$ \\
\hline
\end{tabular}

\section{PVB material}

The polymer of PVB is utilized as the internal layer in laminated glasses. This material shows an Elastic-Plastic behavior in high strain rates occurred under blast loading. Table 3 represents elastic and plastic characteristics of this material (Wu et al. 2010).

Table 3. PVB material characteristics

\begin{tabular}{l|l}
\hline \multicolumn{2}{c}{ PVB characteristics } \\
\hline Density & $1100 \mathrm{~kg} / \mathrm{m}^{3}$ \\
\hline Elasticity module & $530 \mathrm{MPa}$ \\
\hline Shear module & $357 \mathrm{MPa}$ \\
\hline Yield tension & $11 \mathrm{MPa}$ \\
\hline Fail tension & $28 \mathrm{MPa}$ \\
\hline Fail strain & 2 \\
\hline
\end{tabular}




\section{Steel material}

The material of metal sheets is defined as Elastic-plastic (both in pressure and in tension) along with the strain hardening. For the behavior of the steel, material of STEEL4340 available in the AutoDyn library which possesses initial density of $7830 \mathrm{~kg} / \mathrm{m}^{3}$ and Linear statement equation has been employed. In many cases, particularly in solid forms, influence of changes in Entropy is low or overlooked so that the pressure can be assumed only a function of density or special volume. Thus, the linear statement equation can be used for metals. The JohnsonCook resistance is the model applicable for the steel. This model is efficient for explaining the resistance behavior of materials usually metals under high pressures and high strain and tension rates besides high temperature, exactly the behavior occurred under blast loading. The JohnsonCook resistance consists of profile module of 7.7e4 MPa and submission tension of $792 \mathrm{MPa}$. It's stated that disruption criterion of Johnson-Cook has been used for simulation of steel disruption.

\section{Air material}

Air material is applied for simulation of air with the initial density of $1.225 \mathrm{~kg} / \mathrm{m}^{3}$. Applied statement equation for it is the state equation of Ideal Gas used for most gases.

\section{TNT material}

To simulate the explosive material, TNT material available in the AutoDyn library has been utilized for simulation of explosion. Its density equals $1630 \mathrm{~kg} / \mathrm{m}^{3}$ and it has the statement equation of JWL. This statement equation is suitable for description of explosion and expansion of explosive materials.

Following, for meshing the models, the solid elements from SOLID5 have been used to mesh the glass, metal sheets and PVB. This three-D six-side element possesses 8 knots with 6 freedom degree in each knot which is efficient in conditions of large displacement and tensions. Elements contain $5 \mathrm{~cm} \times 5 \mathrm{~cm}$ area and their thicknesses equal thicknesses of laminated glass layers. Figure 1 shows a pattern of this element.

To describe the spring behavior, related element named BEAM161 has been applied. This three-knot

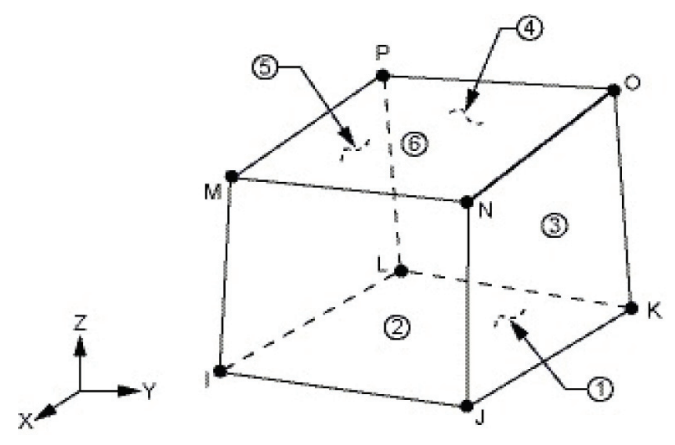

Fig. 1. Solid element
three-D element is applicable in dynamic analyses. Springs possess the length of $0.60 \mathrm{~cm}$, the weight of $5 \mathrm{~kg}$ and the hardness of $17800 \mathrm{~N} / \mathrm{m}$ and the material quality is from STEEL4340.

\section{Geometry of the model}

\subsection{One-layer laminated glass model}

Considered laminated glass consists of four-layer of glass, 2 layers of PVB and 1 layer of air. There is a profile of it in Figure 2.

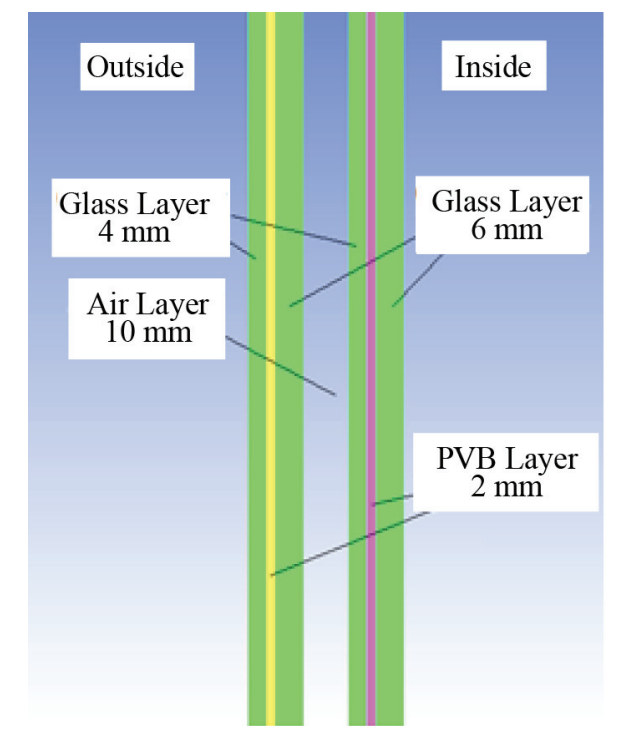

Fig. 2. A section of laminated glass

In this mode, only has one layer of the glass been used with measures of $2 \times 2.70 \mathrm{~m}$. Figure 3 shows threedimensional face of this model.

\subsection{Two-layer laminated glass model}

In this model, there are two layers of laminated glass as internal and external glasses placed in the distance of $0.60 \mathrm{~m}$ from each other that each one of them has 4 layers of the glass and 2 layers of PVB. Dimensions of both layers equal $2 \times 2.70 \mathrm{~m}$.

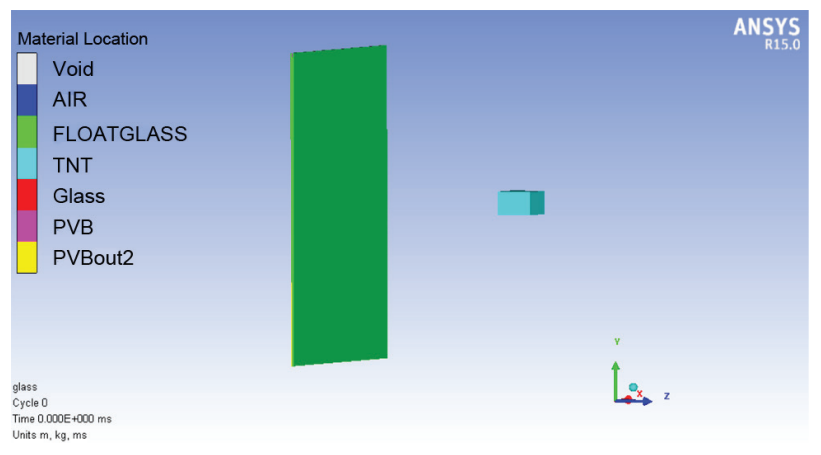

Fig. 3. 3-D face of the one-layer laminated glass 


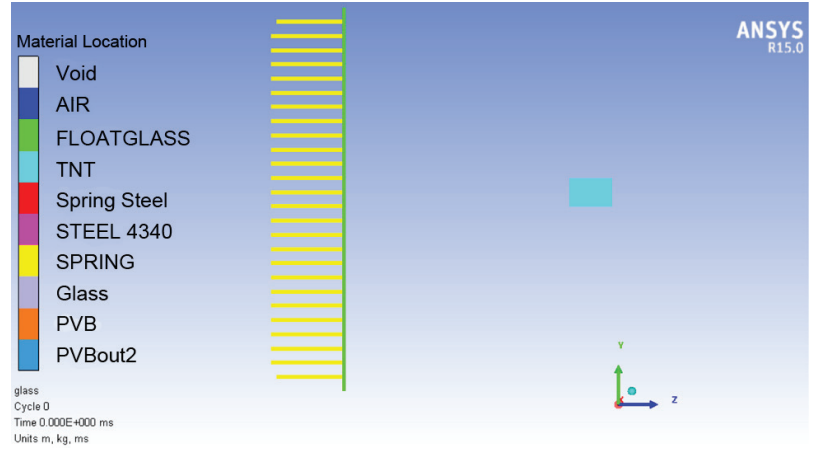

Fig. 4. Lateral face of one-layer laminated glass with spring

\subsection{One-layer laminated glass model with spring}

In the model, the springs with $5 \mathrm{~kg}$ of weight and $17800 \mathrm{~N} / \mathrm{m}$ of hardness have been employed at the back of laminated glass in order to be permitted for more transformation and mortality of blast wave. It's expressed laminated glass in direction of the blast wave doesn't have the base conditions and possesses displacement permission. Figure 4 represents the peripheral face of the model.

\subsection{The model of two-layer laminated glass with spring}

This model is similar to the two-layer laminated glass model means model (2-2) but with springs explained in model (2-3) in the back of the external window frame. This frame is allowed to move in the direction of $\mathrm{Z}$ as the blast direction but the internal window contains the immovable base.

\subsection{The model of two-layer laminated glass with over- lapped anti-blast louvered opening}

In this initiative format in order to prevent and reduce blast waves to inside of the building; three layers were applied including two layers of steel louvered opening with $5 \mathrm{~mm}$ of thickness and one layer of void layer between two opening layers that overlay, all these layers are placed between two laminated glass layers, as both two layers of the curtain are located and surrounded between two opening laminated glass (Fig. 5). These openings possess an overlap of $100 \mathrm{~cm}$.

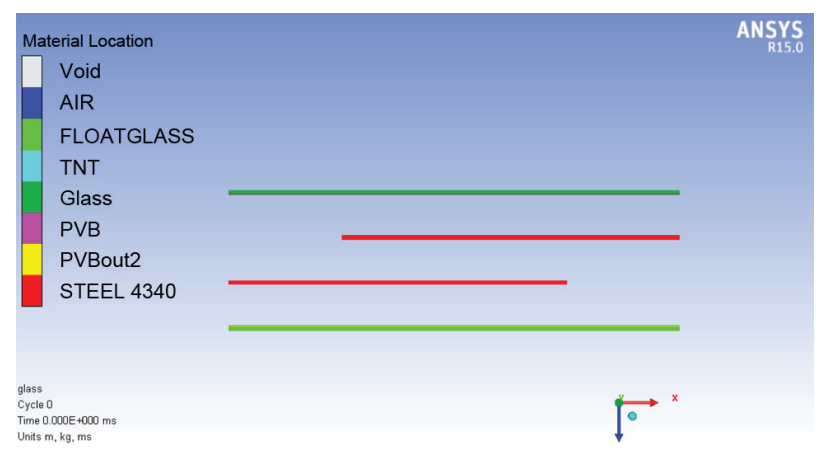

Fig. 5. The plan of two-layer laminated glass with overlapped anti-blast louvered opening

\subsection{The model of two-layer laminated glass with open anti-blast louvered opening}

This model is like the model of two layered laminated glass with overlapped anti blast louvered opening but it does not contain of two layers of overlapped opening and possesses a distance of one meter.

\subsection{The model of two-layer laminated glass with a steel curtain inclusive of $45^{\circ}$}

In this part, the efficiency of the anti-blast louvered curtain in laminated glasses has been assessed. In this model, between two layers of laminated glass having measure equal to $2 \times 2.7 \mathrm{~m}$ a curtain with steel louver or sheets has been used that these sheets possess the length of $2 \mathrm{~m}$, the width of $30 \mathrm{~cm}$ and the thickness of $10 \mathrm{~mm}$. These sheets were considered while they contained $45^{\circ}$ angle. Figure 6 shows the peripheral face of the model.

\subsection{The model of two layered laminated glass with the smart air bag system}

In this model, the smart air bag system has been applied between two layers of laminated glass. The assumption is that in the moment, the blast wave impacts with the external glass layer, the air bag works and the pressure of its inside reaches up to the maximum quantity.

\section{Result}

\subsection{Result of simulation method}

In this section, simulation results of mentioned models of the normal glass are considered.

\section{One-layer laminated glass model (A1)}

Outcomes indicate maximum pressure and impact for laminated glass in this state are $15 \mathrm{MPa}$ and $78 \mathrm{~kg} \cdot \mathrm{m} / \mathrm{ms}$. Besides this, Figure 7 shows that maximum displacement of laminated glass equals $16 \mathrm{~mm}$, because the first location of the glass centre was $0.602 \mathrm{~m}$ and after applying load was $0.586 \mathrm{~m}$.

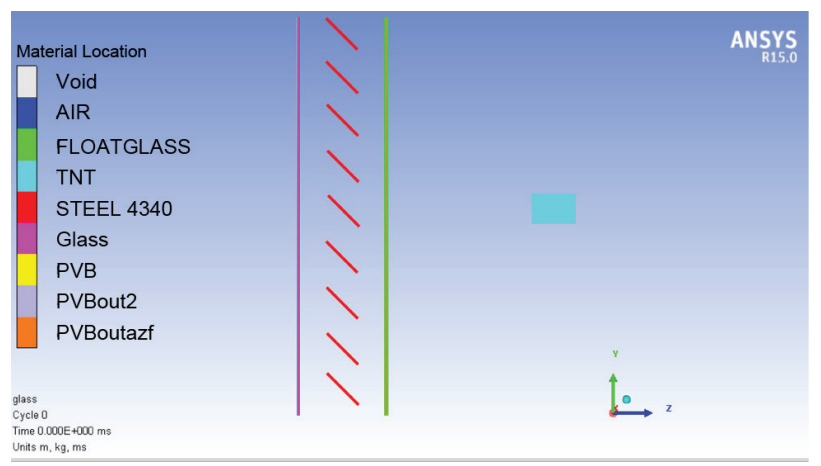

Fig. 6. Lateral face of two-layer laminated glass with steel curtain of $45^{\circ}$ angle 
Pressure History

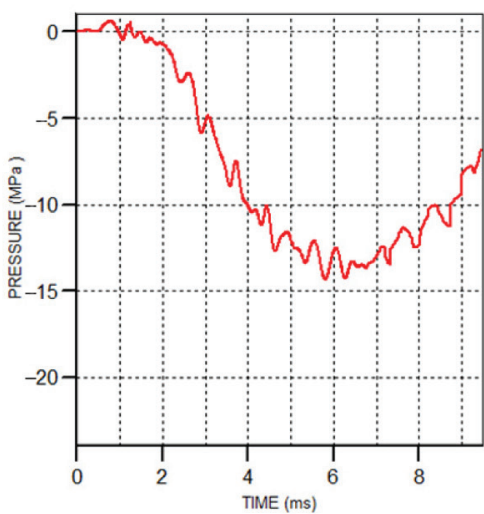

Impact History

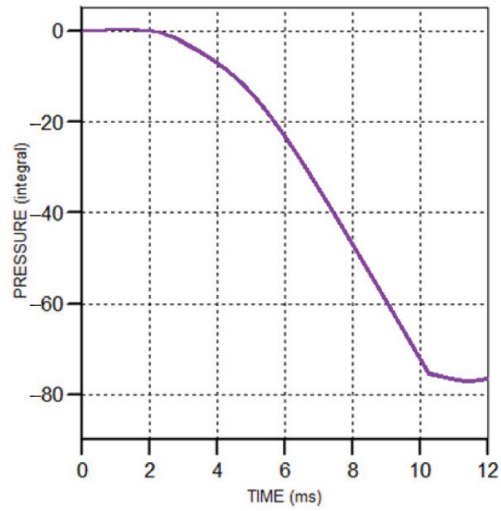

Displacement History

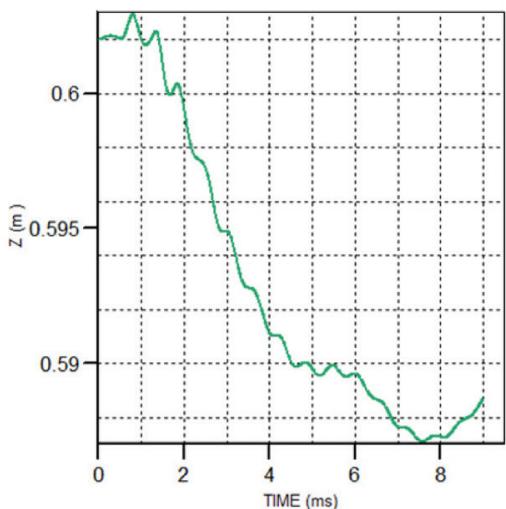

Fig. 7. Time history graphs of pressure, impact and maximum displacement in one-layer laminated glass

\section{Two-layer laminated glass model (A2)}

Maximum pressure and impact of the internal laminated glass in this position are $9 \mathrm{MPa}$ and $42 \mathrm{~kg} . \mathrm{m} / \mathrm{ms}$ showing reduction quantity of these parameters as opposed to onelayer laminated glass. Therefore, maximum displacement of the internal laminated glass reaches $14 \mathrm{~mm}$ means reduction of $2 \mathrm{~mm}$.

The model of one-layer laminated glass with spring (A3)

In this position, maximum pressure and impact on the laminated glass equal $14 \mathrm{MPa}$ and $78 \mathrm{~kg} . \mathrm{m} / \mathrm{ms}$ that have the quantities similar to the one-layer laminated glass. However, the significant point is that application of the springs in the back of window frame causes raising the resistance in the laminated glass; because the frame does not possess an immovable base and with regard to the springs it can be displaced in direction of blast wave performance. Maximum absolute displacement of laminated and the spring are $41.5 \mathrm{~mm}$ for laminated glass and $32 \mathrm{~mm}$ for the spring and as a result, relative displacement of the glass is about $9.5 \mathrm{~mm}$.

The model of two layered laminated glass with spring (A4)

In this state, maximum pressure and impact on the internal laminated glass equal $5 \mathrm{MPa}$ and $16 \mathrm{~kg} . \mathrm{m} / \mathrm{ms}$ that compared with previous models indicates maximum decline in the pressure and impact. In addition, maximum displacement of laminated glass equals $7 \mathrm{~mm}$.

The model of two-layer laminated glass with the overlapped anti-blast louvered opening (A5)

In this model, as expected, a very small pressure and impact have been inflicted on the internal laminated glass; so that the maximum displacement of the glass equals zero.
The model of two layered laminated glass with open antiblast louvered opening (A6)

In this model, maximum pressure and impact for the internal laminated glass in this position equal $19 \mathrm{MPa}$ and $110 \mathrm{~kg} . \mathrm{m} / \mathrm{ms}$ that demonstrate the increase of these two parameters compared to previous models. Maximum transformation of the laminated glass in this mode equals about $31 \mathrm{~mm}$.

Two-layer laminated glass model with $45^{\circ}$ steel curtain (A7)

In this form, the steel curtain causes reduction of the pressure and impact to $7 \mathrm{MPa}$ and $40 \mathrm{~kg} . \mathrm{m} / \mathrm{ms}$. Maximum displacement in this situation equals within $11.5 \mathrm{~mm}$.

Two-layer laminated glass with the smart air bag system (A8)

In this condition, maximum pressure and impact for the laminated glass equal $10 \mathrm{MPa}$ and $18 \mathrm{~kg} . \mathrm{m} / \mathrm{ms}$. Furthermore, the maximum displacement of laminated glass is about $9 \mathrm{~mm}$.

\subsection{Result of AHP method}

In Table 3 the importance degrees of assessment indexes for all resistant laminated glass façades are compared. According to the results of the questionnaire, the index of resistance against explosion with the weight of 0.614 possesses the most weight and the passed light degree

Table 3. Importance degree of assessment indexes and selection of different resistant glass facades against the explosion

\begin{tabular}{l|c|c|c|c|c|c}
\hline Index & $\mathrm{X} 1$ & $\mathrm{X} 2$ & $\mathrm{X} 3$ & $\mathrm{X} 4$ & $\mathrm{X} 5$ & Weights \\
\hline $\mathrm{X} 1$ & 1 & 5.02 & 6.97 & 7.04 & 7.02 & 0.614 \\
\hline $\mathrm{X} 2$ & & 1 & 3.12 & 2.92 & 3.39 & 0.123 \\
\hline $\mathrm{X} 3$ & & & 1 & 0.98 & 1.03 & 0.088 \\
\hline $\mathrm{X} 4$ & & & & 1 & 1.01 & 0.088 \\
\hline $\mathrm{X} 5$ & & & & & 1 & 0.088 \\
\hline
\end{tabular}


Table 4. Importance degree of assessment indexes and selection of index of resistance against explosion

\begin{tabular}{l|l|l|l|l}
\hline $\begin{array}{c}\text { Index of } \\
\text { resistance against } \\
\text { explosion }\end{array}$ & $\begin{array}{c}\text { Maximum } \\
\text { occurred } \\
\text { pressure }\end{array}$ & $\begin{array}{c}\text { Occurred } \\
\text { impact }\end{array}$ & $\begin{array}{c}\text { Damage } \\
\text { of } \\
\text { explosion }\end{array}$ & weight \\
\hline $\begin{array}{l}\text { Maximum pres- } \\
\text { sure }\end{array}$ & 1 & 1 & 0.143 & 0.11 \\
\hline Impact & 1 & 0.143 & 0.11 \\
\hline $\begin{array}{l}\text { Damage of } \\
\text { explosion }\end{array}$ & & 1 & 0.78 \\
\hline$C R=0.00$ & & & &
\end{tabular}

with 0.123 has the second rank. Next indexes with notable distance in comparison with two previous indexes possess equal weights. Table 4 has compared beneath resistance index including maximum pressure, impact and damage resulted by the explosion that shows the remarkable weight of 0.78 for damage and 0.11 for pressure and impact.

Table 5 represents the preference degree of considered models for laminated glasses (based on maximum pressure index) from the experts' perspectives. In the table are eight laminated glass models as following:

- Model (A1) - one-layer laminated glass;

- Model (A2) - two-layer laminated glass;
- Model (A3) - one-layer laminated glass with the spring;

- Model (A4) - two-layer laminated glass with the spring;

- Model (A5) - two-layer laminated glass with overlapped anti-blast louvered opening;

- Model (A6) - two-layer laminated glass with open anti-blast louvered opening;

- Model (A7) - two-layer laminated glass with the $45^{\circ}$ steel curtain;

- Model (A8) - two-layer laminated glass with the air bag.

On the basis of Table 5 results, Model (A5) with the weight of 0.310 was the best model and Model (A4) with the weight of 0.207 was after that. Next, Model (A7) with the weight of 0.172 was the third model. In this index, Model (A6) was the worst model with the weight of 0.014 .

Table 6 presents the importance degree of any laminated glass models related to maximum impact from the experts' opinions. According to the table, Model (A5), was the best model with weight of 0.265 and Model (A4) was located at the second category with weight of 0.210 . Model (A6) was the weakest model in this index with the weight of 0.008 .

Table 5. Importance degree of any laminated glass models related to pressure of explosion

\begin{tabular}{c|c|c|c|c|c|c|c|c|c}
\hline $\begin{array}{c}\text { Comparison matrix } \\
\text { of maximum pressure }\end{array}$ & A1 & A2 & A3 & A4 & A5 & A6 & A7 & A8 & Weights \\
\hline A1 & 1 & 0.277 & 1.020 & 0.166 & 0.111 & 2.499 & 0.198 & 0.333 & 0.034 \\
\hline A2 & & 1 & 5.011 & 0.251 & 0.125 & 8.997 & 0.496 & 1.504 & 0.124 \\
\hline A3 & & & 1 & 0.167 & 0.143 & 3.011 & 0.199 & 0.385 & 0.034 \\
\hline A4 & & & & 1 & 0.143 & 8.997 & 2.003 & 5.012 & 0.207 \\
\hline A5 & & & & & 1 & 8.989 & 9.021 & 9.011 & 0.310 \\
\hline A6 & & & & & & 1 & 0.211 & 0.250 & 0.014 \\
\hline A7 & & & & & & & 1 & 3.012 & 0.172 \\
\hline A8 & & & & & & & & 1 & 0.103 \\
\hline
\end{tabular}

$\overline{C R}=0.08$.

Table 6. Importance degree of any laminated glass models related to maximum impact

\begin{tabular}{c|c|c|c|c|c|c|c|c|c}
\hline $\begin{array}{c}\text { Comparison matrix } \\
\text { of impact }\end{array}$ & A1 & A2 & A3 & A4 & A5 & A6 & A7 & A8 & Weights \\
\hline A1 & 1 & 0.241 & 1.011 & 0.139 & 0.112 & 3.698 & 0.238 & 0.145 & 0.029 \\
\hline A2 & & 1 & 4.151 & 0.178 & 0.111 & 7.997 & 0.996 & 0.166 & 0.122 \\
\hline A3 & & & 1 & 0.167 & 0.112 & 4.011 & 0.251 & 0.167 & 0.029 \\
\hline A4 & & & & 1 & 0.144 & 6.997 & 4.012 & 2.987 & 0.210 \\
\hline A5 & & & & & 1 & 8.994 & 8.013 & 7.012 & 0.265 \\
\hline A6 & & & & & & 1 & 0.202 & 0.196 & 0.008 \\
\hline A7 & & & & & & & 1 & 0.252 & 0.130 \\
\hline A8 & & & & & & & & 1 & 0.206 \\
\hline
\end{tabular}

$C R=0.07$. 
Table 7. Importance degree of any laminated glass models related to damage from explosion

\begin{tabular}{c|c|c|c|c|c|c|c|c|c}
\hline Comparison matrix of damage from explosion & A1 & A2 & A3 & A4 & A5 & A6 & A7 & A8 & Weights \\
\hline A1 & 1 & 0.885 & 0.270 & 0.202 & 0.111 & 8.501 & 0.398 & 0.251 & 0.038 \\
\hline A2 & & 1 & 0.333 & 0.222 & 0.125 & 9.012 & 0.333 & 0.250 & 0.043 \\
\hline A3 & & & 1 & 0.498 & 0.166 & 7.987 & 1.503 & 1.012 & 0.140 \\
\hline A4 & & & & 1 & 0.247 & 8.985 & 3.012 & 1.492 & 0.189 \\
\hline A5 & & & & & 1 & 8.991 & 4.973 & 5.982 & 0.340 \\
\hline A6 & & & & & & 1 & 0.251 & 0.197 & 0.004 \\
\hline A7 & & & & & & & 1 & 0.511 & 0.095 \\
\hline A8 & & & & & & & & 1 & 0.151 \\
\hline
\end{tabular}

$\mathrm{CR}=0.05$.

Table 8. Importance degree of any laminated glass models related to passed light degree

\begin{tabular}{c|c|c|c|c|c|c|c|c|c}
\hline Comparison matrix of passed light & A1 & A2 & A3 & A4 & A5 & A6 & A7 & A8 & Weights \\
\hline A1 & 1 & 3.012 & 0.998 & 2.987 & 7.986 & 5.012 & 5.003 & 1.995 & 0.271 \\
\hline A2 & & 1 & 0.497 & 1.012 & 5.987 & 3.012 & 2.013 & 1.996 & 0.090 \\
\hline A3 A4 & & & 1 & 0.502 & 7.014 & 4.012 & 2.986 & 2.031 & 0.271 \\
\hline A5 & & & & 1 & 6.012 & 3.031 & 2.012 & 2.011 & 0.090 \\
\hline A6 & & & & & 1 & 0.332 & 0.496 & 0.197 & 0.034 \\
\hline A7 & & & & & & 1 & 2.013 & 0.511 & 0.054 \\
\hline A8 & & & & & & & 1 & 1.996 & 0.054 \\
\hline
\end{tabular}

$C R=0.03$.

Table 9. Importance degree of any laminated glass models related to implementation expenditure

\begin{tabular}{c|c|c|c|c|c|c|c|c|c}
\hline Comparison matrix of implementation expenditure & A1 & A2 & A3 & A4 & A5 & A6 & A7 & A8 & Weights \\
\hline A1 & 1 & 3.012 & 2.013 & 3.987 & 8.012 & 6.011 & 4.993 & 7.012 & 0.368 \\
\hline A2 & & 1 & 0.502 & 1.985 & 4.967 & 2.985 & 2.012 & 4.013 & 0.123 \\
\hline A3 & & & 1 & 1.999 & 6.012 & 3.987 & 3.213 & 5.108 & 0.184 \\
\hline A4 & & & & 1 & 4.012 & 2.011 & 1.984 & 3.021 & 0.092 \\
\hline A5 A6 & & & & & 1 & 0.502 & 0.333 & 0.495 & 0.046 \\
\hline A7 & & & & & & 1 & 0.503 & 1.513 & 0.061 \\
\hline A8 & & & & & & & 1 & 2.021 & 0.074 \\
\hline
\end{tabular}

$\overline{C R}=0.05$.

Following, Table 7 illustrates the superiority degree of considered models in terms of damage index. On the basis of experts' opinion, Model (A5) had the minimum damage with the weight of 0.340 and Model (A4) and (A8) were after that with the weight of 0.189 and 0.151 , respectively. The maximum damage was related to Model (A6).

Table 8 represents the importance degree of any laminated glass models related to passed light degree. According to the table, Model (A1) and (A3) provided the most light with the weight of 0.271 and after those, Model (A8) was located at the second category. Model (A5) provided the least light with the weight of 0.034 .
In Table 9, the comparison between alternatives in terms of expenditure index has been performed. On the basis of the table results, the least cost was related to Model (A1) with the weight of 0.368 . Next, Model (A3) was located at the second category with the weight of 0.184 and the noticeable point was that Model (A5) was the most expensive model.

Tables 10 and 11 had similar results because complexity certainly decreases the speed of implementation. Model (A1) was the easiest and fastest model with the weight of 0.368 . However, Model (A5) had the most difficult and least speed implementation with the weight of 0.046 . 
Table 10. Importance degree of any laminated glass models related to implementation complexity

\begin{tabular}{c|c|c|c|c|c|c|c|c|c}
\hline Comparison matrix of implementation complexity & A1 & A2 & A3 & A4 & A5 & A6 & A7 & A8 & Weights \\
\hline A1 & 1 & 1.987 & 2.997 & 4.013 & 5.992 & 5.023 & 6.987 & 8.012 & 0.368 \\
\hline A2 & & 1 & 0.996 & 4.021 & 2.512 & 5.013 & 2.013 & 2.491 & 0.184 \\
\hline A3 & & & 1 & 1.976 & 5.989 & 4.012 & 3.222 & 5.102 & 0123 \\
\hline A4 & & & & 1 & 4.014 & 2.010 & 1.991 & 3.016 & 0.092 \\
\hline A5 & & & & & 1 & 0.502 & 0.334 & 0.498 & 0.061 \\
\hline A6 & & & & & & 1 & 0.505 & 1.522 & 0.074 \\
\hline A7 & & & & & & & 1 & 1.988 & 0.053 \\
\hline
\end{tabular}

$\overline{C R}=0.09$.

Table 11. Importance degree of any laminated glass models related to implementation speed

\begin{tabular}{c|c|c|c|c|c|c|c|c|c}
\hline Comparison matrix of implementation speed & A1 & A2 & A3 & A4 & A5 & A6 & A7 & A8 & Weights \\
\hline A1 & 1 & 1.989 & 2.997 & 4.015 & 5.988 & 7.011 & 4.996 & 8.012 & 0.368 \\
\hline A2 & & 1 & 0.998 & 4.014 & 2.993 & 5.013 & 2.013 & 2.491 & 0.184 \\
\hline A3 & & & 1 & 1.976 & 5.989 & 4.012 & 3.222 & 5.102 & 0.123 \\
\hline A4 & & & & 1 & 4.011 & 2.016 & 1.981 & 3.020 & 0.092 \\
\hline A5 A6 & & & & & 1 & 0.512 & 0.333 & 0.495 & 0.061 \\
\hline A7 & & & & & & 1 & 0.502 & 1.502 & 0.053 \\
\hline A8 & & & & & & & 1 & 1.998 & 0.073 \\
\hline
\end{tabular}

$C R=0.07$.

\section{Discussion}

\subsection{Comparison of simulation results}

In this section, outcomes of the eight laminated glass models stated in the previous section have been compared. First, in Figure 8 maximum pressures resulted from the explosion for these eight models have been compared. One-layer laminated glass model (A1) possesses maximum pressure of $15 \mathrm{MPa}$. In addition, onelayer laminated glass model with spring (A3) possesses nearly this pressure degree and as expected it does not affect the pressure. Afterwards, the model of the smart air bag system (A8) has almost as effect as two-layer laminated glass model (A2) in reduction of pressure and they include of maximum pressures of $10 \mathrm{MPa}$ and $9 \mathrm{MPa}$, in order. The model of steel curtain with a $45^{\circ}$ angle (A7) has more influence on pressure alleviation as opposed to previous models and decreases the pressure to $7 \mathrm{MPa}$. The model of two-layer laminated glass with spring (A4) could decline the pressure to $5 \mathrm{MPa}$, too. But the best function, as expected, belongs to the model of overlapped louvered opening (A5) which permits passing of only $0.1 \mathrm{MPa}$ of the pressure. The important point is the function of open louvered opening model (A6) that causes escalation of the pressure to $19 \mathrm{MPa}$ and possesses a raising effect on the pressure because of creation of blast wave reflection between the laminated glass and louvered openings and as a result, enhancement of occurred pressure.

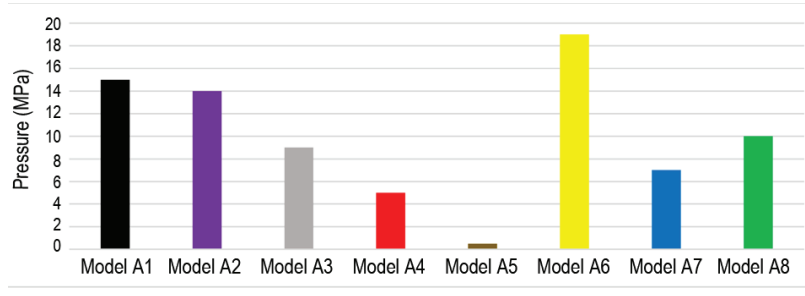

Fig. 8. Comparison chart of maximum quantities of occurred pressure for eight laminated glass models

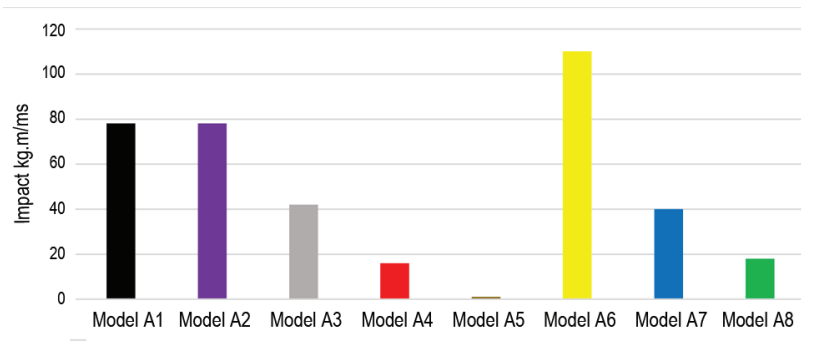

Fig. 9. Comparison chart of occurred impact on eight laminated glass models

However, comparing the impact shown in Figure 9 indicates, that the models of one-layer laminated glass (A1) and one-layer laminated glass with spring (A3) possess the equal impacts of $78 \mathrm{~kg} \cdot \mathrm{m} / \mathrm{ms}$. Two-layer laminated glass (A2) could decline the impact to $42 \mathrm{~kg} . \mathrm{m} / \mathrm{ms}$. The steel curtain of $45^{\circ}$ (A7) contains the impact of $40 \mathrm{~kg} . \mathrm{m} / \mathrm{ms}$ which couldn't create more difference in 


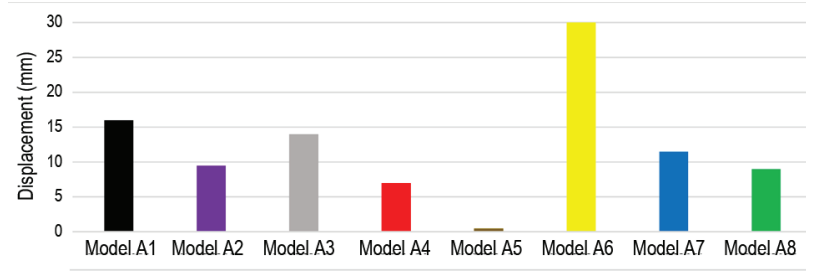

Fig. 10. Comparison chart of maximum relative displacement for eight laminated glass models

impact reduction by comparison with the two-layer laminated glass (A2). The models of smart air bag system (A8) and two-layer laminated glass with spring (A4) had better functions and could alleviate the impact to $18 \mathrm{~kg} \cdot \mathrm{m} / \mathrm{ms}$ and $16 \mathrm{~kg} . \mathrm{m} / \mathrm{ms}$, in order; although the best reduction in the impact again belongs to overlapped louvered opening model (A5) with the impact of nearly $0.3 \mathrm{~kg} . \mathrm{m} / \mathrm{ms}$.

But, open louvered opening model (A6) again possesses raising influence on the impact and enhances it to $110 \mathrm{~kg} . \mathrm{m} / \mathrm{ms}$.

Figure 10 demonstrates maximum displacement of the laminated glass in direction of blast wave dispersal. As observed in the Figure 10, maximum displacement of one-layer laminated glass (A1) is $16 \mathrm{~mm}$. The least effect belongs to the one-layer laminated glass with spring (A3) with $14 \mathrm{~mm}$ which causes very small reduction. The model steel curtain with $45^{\circ}$ (A7) has the displacement of $11.5 \mathrm{~mm}$. In addition, the models of two-layer laminated glass (A2) and smart air bag system (A8) contain the equal reduction of displacement with the relative quantity of $9 \mathrm{~mm}$. Two-layer laminated glass with spring (A4) works better than previous models because of displacement of $7 \mathrm{~mm}$ and lastly, the most reduction of displacement again belongs to overlapped louvered opening model (A5), approximately without displacement. As pointed above, because the pressure and impact of model (A6) are higher than others, certainly its displacement is more than other models and is $30 \mathrm{~mm}$.

Therefore, basing on Figure 11, the best function among laminated glass models belongs to the overlapped louvered opening model (A5). The next is the model of two-layer laminated glass with spring (A4) that possesses the reductions of $67 \%, 79 \%$ and $56 \%$ in the pressure, impact and displacement. The models of smart air bag sys-

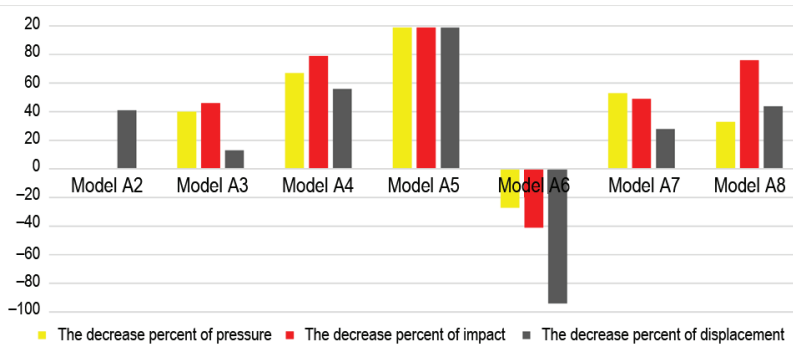

Fig. 11. Comparison chart of reduction percentage of maximum pressure, impact and displacement for laminated glass models as opposed to one-layer laminated glass model
Table 12. Ranking of laminated glass models based on safety provided by them

\begin{tabular}{|c|c|}
\hline Rank & Model \\
\hline First & $\begin{array}{c}\text { Two-layer laminated glass with overlapped anti- } \\
\text { blast louvered opening (A5) }\end{array}$ \\
\hline Second & Two-layer laminated glass with spring (A4) \\
\hline Third & $\begin{array}{l}\text { Two-layer laminated glass with air bag (A8) } \\
\text { One-layer laminated glass with spring (A3) } \\
\text { Two-layer laminated glass with } 45 \text { steel curtain (A7) }\end{array}$ \\
\hline Fourth & Two-layer laminated glass (A2) \\
\hline Fifth & One-layer laminated glass (A1) \\
\hline
\end{tabular}

tem (A8) and one-layer laminated glass with the spring (A3) are placed in the next ranks with nearly reductions of $44 \%$ and $41 \%$ in maximum displacement. $45^{\circ}$ steel curtain model (A7) can be located in the subsequent rank with reductions of $53 \%, 49 \%$ and $28 \%$ in the pressure, impact and displacement; but the least influence can be found in two-layer laminated glass model (A2) with reductions of $40 \%, 46 \%$ and $13 \%$ in the pressure, impact and displacement.

As expressed, open louvered opening (A6) contains an inverted effect on the function of the model and causes increases of $27 \%, 41 \%$ and $94 \%$ in the pressure, impact and displacement.

Table 12 indicates ranking of laminated glass models; so that the first rank has the most safety amount and the fifth rank contains the least safety quantity among the eight laminated glass modes.

\subsection{Comparison of AHP results}

In Figure 12 weights of eight laminated glass models have been compared that the most weight belongs to the model of two-layer laminated glass with overlapped steel louvered opening (A5) with the weight of 0.211.

\section{Conclusions}

The main results of the study are listed as following:

1) It's observed that strength of the internal layer has an important effect on the laminated glass response under intense blast loading. The laminated glass must be designed in a way that not disrupted by cracking of the middle layer to provide maximum desirable safety.

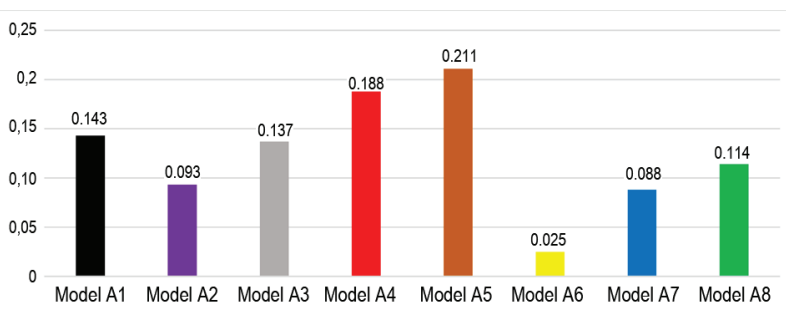

Fig. 12. Comparison chart of weights of eight laminated glass models in AHP method 
2) The significant point is that panels must be designed in a way in which failure and disruption of the glass and its internal layer occur before disruption of bases means the frame zone to provide desirable safety level. Thus, material properties of the glass, internal glass and seal in interconnection of the glass to the frame play the important role in the blast resistance.

3) Application of the spring and mortality in the back of normal glasses because of brittleness and fragility of the glass does not affect the injury reduction, whereas springs in laminated glasses because of their high plasticity properties are very affective.

4) The best function among laminated glass models belongs to the overlapped louvered opening model as it is true in normal glass models. Afterwards, there is the model of two-layer laminated glass with spring. According to experts' opinions, the models of onelayer laminated glass and one-layer laminated glass with spring provide the lightest degree for the internal space. Afterwards, the models of two-layer laminated glass and two-layer laminated glass with spring are placed. The models of smart air bag system, $45^{\circ}$ steel curtain and open and overlapped louvered openings are in the next ranks.

Based on experts' opinions, one-layer laminated glass, considering implementation expenditure, is the most economical model and one-layer laminated model with spring is placed in the next position. Models of two-layer laminated glass, two-layer laminated glass with spring, $45^{\circ}$ steel curtain, open and closed louvered openings and smart air bag are located in next places.

On the base of experts' ideas, with regard to two criteria of complexity and implementation speed, one-layer laminated glass model again obtained the first position. Two-layer laminated glass gained the second place and the models of one-layer laminated glass with spring and two-layer laminated glass with spring are placed in the third and fourth ranks. The models of open and closed louvered openings, steel curtain and smart air bag system possess the worst situations among the models.

Among laminated glass models, the most economical model supplying the most light besides the most safety is the model of one-layer laminated glass.

The outcomes of the paper, not only, would be certainly beneficial and useful to build and perform new buildings, but also to retrofit facades of existing buildings and can have application for both buildings. Especially, these results can apply to retrofit vital and sensitive centres that should have glass façade because of reasons for instance light or aesthetic. Surely, the research in this field can be continued and other ways can be presented to mitigate the effects of blast on glass façade buildings for example research on glass material and increasing its tensile strength, performing connection between glass and its frame and also between frame and wall as better as.

\section{References}

ASTM E 1300-09a. Standard practice for determining load resistance of glass in buildings. West Conshohocken, PA: ASTM International, 2010. 61 p.

ASTM F 2248-09. Standard practice for specifying an equivalent 3-second duration design loading for blast resistant glazing fabricated with laminated glass. West Conshohocken, PA: ASTM International, 2010. 4 p.

Badri, M. A. 2001. A combined AHP-GP model for quality control systems, International Journal of Production Economics 72(1): 27-40. http://dx.doi.org/10.1016/S0925-5273(00)00077-3

Beason, W. L.; Morgan, J. R. 1984. Glass failure prediction model, Journal of Structure Engineering 110(2): 197-212.

http://dx.doi.org/10.1061/(ASCE)0733-9445(1984)110:2(197)

Bedon, C.; Amadio, C.; Sinico, A. 2014. Numerical and analytical investigation on the dynamic buckling behavior of glass columns under blast, Engineering Structures 79: 322-340. http://dx.doi.org/10.1016/j.engstruct.2014.08.024

Bitarafan, M.; Hashemkhani, S.; Arefi, S.; Zavadskas, E. K. 2012. Evaluating the construction methods of cold-formed steel structures in reconstructing the areas damaged in natural crises, using the methods AHP and COPRAS-G, Archives of Civil and Mechanical Engineering 12(3): 360367. http://dx.doi.org/10.1016/j.acme.2012.06.015

Borg, W. R.; Gall, M. D. 1989. Educational research. $5^{\text {th }}$ ed. NewYork: Longman. 704 p.

Dağdeviren, M. 2008. Decision making in equipment selection: an integrated approach with AHP and PROMETHEE, Journal of Intelligent Manufacturing 19(4): 397-406. http://dx.doi.org/10.1007/s10845-008-0091-7

Gudienè, N.; Banaitis, A.; Podvezko, V.; Banaitienè, N. 2014. Identification and evaluation of the critical success factors for construction projects in Lithuania: AHP approach, Journal of Civil Engineering and Management 20(3): 350-359.

http://dx.doi.org/10.3846/13923730.2014.914082

Hidallana-Gamage, H. D.; Thambiratnam, D. P.; Perera, N. J. 2013a. Computational analysis of laminated glass panels under blast loads: a comparison of two dimensional and three dimensional modeling approaches, The International Journal of Engineering and Science 2(8): 69-79.

Hidallana-Gamage, H. D.; Thambiratnam, D. P.; Perera, N. J. 2013b. Response of a building envelope system to near field blast events. In: The fifth international conference on structural engineering, mechanics and computation, in Proceedings of the Fifth International Conference on Structural Engineering, Mechanics and Computation: Research and Applications in Structural Engineering, Mechanics and Computation, 2-4 September 2013, Cape Town, South Africa. 5 p. http://dx.doi.org/10.1201/b15963-97

Hidallana-Gamage, H. D.; Thambiratnam, D. P.; Perera, N. J. 2014a. Failure analysis of laminated glass panels subjected to blast loads, Engineering Failure Analysis 36: 14-29. http://dx.doi.org/10.1016/j.engfailanal.2013.09.018

Hidallana-Gamage, H. D.; Thambiratnam, D. P.; Perera, N. J. 2014b. Numerical modelling and analysis of the blast performance of laminated glass panels and the influence of material parameters, Engineering Failure Analysis 45: 65-84. http://dx.doi.org/10.1016/j.engfailanal.2014.06.013

Holmquist, T. J.; Johnson, G. R.; Lopatin, C.; Grady, D.; Hertel, J. 1995. High strain rate properties and constitutive modeling of glass, in 15th International Symposium on Ballistics, 21-24 May 1995, Jerusalem, Israel. 15 p. 
Hooper, P. A.; Sukhram, R. A. M.; Blackman, B. R. K.; Dear, J. P. 2012. On the blast resistance of laminated glass, International Journal of Solids and Structures 49(6): 899918. http://dx.doi.org/10.1016/j.ijsolstr.2011.12.008

Işıklar, G.; Büyüközkan, G. 2007. Using a multi-criteria decision making approach to evaluate mobile phone alternatives, Computer Standards \& Interfaces 29(2): 265-274. http://dx.doi.org/10.1016/j.csi.2006.05.002

Kranzer, C.; Gürke, G.; Mayrhofer, C. 2005. Testing of bomb resistant glazing systems experimental investigations of the time dependent deflection of blast loaded $7.5 \mathrm{~mm}$ laminated glass, in Glass Processing Days, 31 August 2005, Germany: Fraunhofer Institute for High-Speed Dynamics, Ernst-Mach-Institut in Efringen-Kirchen. 7 p.

Larcher, M.; Solomos, G.; Casadei, F.; Gebbeken, N. 2012. Experimental and numerical investigations of laminated glass subjected to blast loading, International Journal of Impact Engineering 39(1): 42-50. http://dx.doi.org/10.1016/j.ijimpeng.2011.09.006

Lusk, B.; Salim, H.; Perry, K.; Nawar, M.; Wedding, W. C.; Kiger, S. 2011. Modelling and testing of laminated window systems under blast loading, in Structures Congress, 14-16 April 2011, Las Vegas, Nevada, United States. ASCE, 1552-1560.

Nakhaei, J.; Bitarafan, M.; Lale Arefi, Sh. 2015. Choosing the best urban tunnels as safe space in crisis using AHP method: a case study in Iran, Journal of Architecture and Urbanism 39(2): 149-160.

http://dx.doi.org/10.3846/20297955.2015.1056439

Overend, M.; Zammit, K. 2012. A computer algorithm for determining the tensile strength of float glass, Engineering Structures 45: 68-77. http://dx.doi.org/10.1016/j.engstruct.2012.05.039

Peroni, M.; Solomos, G.; Pizzinato, V.; Larcher, M. 2011. Experimental investigation of high strain-rate behaviour of glass, Applied Mechanics and Materials 82: 63-68. http://dx.doi.org/10.4028/www.scientific.net/AMM.82.63

Polat, G. 2015. Subcontractor selection using the integration of the AHP and PROMETHEE methods, Journal of Civil Engineering and Management. http://dx.doi.org/10.3846/13923730.2014.948910
Saati, T. L.; Wind, Y. 1980. Marketing applications of the Analytic Hierarchy Process, Management Science 26(7): 641658. http://dx.doi.org/10.1287/mnsc.26.7.641

Smith, D. C. 2001. Glazing for injury alleviation under blast loading: United Kingdom practice, in Glass Processing Days, 18-21 June 2001, Tampere, Finland, 335-340.

UK glazing hazard guide. 1997. SAFE/SSG. Explosive protection. London. SSG/EP/4/97.

UFC 3-340-02. Structures to resist the effect of accidental explosions. Washington DC., USA: US Department of Defense, 2008. $12 \mathrm{p}$.

UFC 4-010-01. Antiterrorism standards for buildings. Washington DC., USA: US Department of Defense, 2013. 99 p.

Wang, J. J.; Yang, D. L. 2007. Using a hybrid multi-criteria decision aid method for information systems outsourcing, Computers \& Operations Research 34(12): 3691-3700. http://dx.doi.org/10.1016/j.cor.2006.01.017

Wang, W.; Yu, W.; Yang, I.; Lin, C.; Lee, M.; Cheng, Y. 2013. Applying the AHP to support the best-value contractor selection - lessons learned from two case studies in Taiwan, Journal of Civil Engineering and Management 19(1): 2436. http://dx.doi.org/10.3846/13923730.2012.734851

Wei, J.; Shetty, M. S.; Dharani, L. R. 2006. Failure analysis of architectural glazing subjected to blast loading, Engineering Failure Analysis 13(7): 1029-1043. http://dx.doi.org/10.1016/j.engfailanal.2005.07.010

Wu, C. D.; Yan, X. Q.; Shen, L. M. 2010. A numerical study on dynamic failure of nanomaterial enhanced laminated glass under impact, IOP Conference Series: Materials Science and Engineering 10(1): 1-10. http://dx.doi.org/10.1088/1757-899x/10/1/012176

Zhang, X.; Zou, Y.; Hao, H.; Li, X.; Ma, G.; Liu, K. 2012. Laboratory test on dynamic materialproperties of annealed float glass, International Journal of Protective Structures 3(4): 407-430. http://dx.doi.org/10.1260/2041-4196.3.4.407

Zhang, X.; Hao, H.; Ma, G. 2013. Parametric study of laminated glass window response to blast loads, Engineering Structures 56: 1707-1717. http://dx.doi.org/10.1016/j.engstruct.2013.08.007

Jalal NAKHAEI. Department of Art and Architecture Engineering in Islamic Azad University, Central Tehran Branch, Iran. Research interests: architecture engineering, crisis management, safe spaces and structures.

Saeed FORGHANI. Master of Science in Department of Civil Engineering in Malek Ashtar University of Technology, Tehran, Iran. Research interests: civil engineering, earthquake engineering, multiple criteria, explosion protection, Simulation method.

Mahdi BITARAFAN. Department of Civil Engineering in Research Institute of Shakhes Pajouh, Isfahan, Iran. Research interests: civil engineering, earthquake engineering, multiple criteria decision making, explosion protection.

Shahin LALE AREFI. Department of Civil Engineering in University of Mohaghegh Ardabili, Ardabil, Iran. Research interests: civil engineering, earthquake engineering, damage detection, experimental, composite materials, retrofitting and strengthening on steel and concrete structures, multiple criteria decision making.

Jonas ŠAPARAUSKAS. Doctor, Associate Professor. Department of Construction Technology and Management, Vilnius Gediminas Technical University. First degree in civil engineering, Vilnius GediminasTechnical University (1997). Master of Science (1999). Doctor (2004). Research visits to Leipzig Higher School of Technology, Economics and Culture (Germany, 2000 and 2001) and Eindhoven University of Technology (The Netherlands, 2002). Researcher in International Project "Inteligent cities" (2004), Member of the EWG-MCDA Working Group within EURO since 2002. Author of more than 15 scientific articles. Research interests: construction technology and organisation, project management, multiple criteria decision making and sustainable urban development. 